\title{
MAMPIR NGOMBE: \\ REFLEKSI DI TENGAH PANDEMI COVID-19 MELALUI FILM TARI
}

\author{
Arjuni Prasetyorini \\ Prodi Tari, Fakultas Seni Pertunjukan, Institut Seni Indonesia Yogyakarta \\ Email: arjuni.prasetyorini@isi.ac.id
}

\section{RINGKASAN}

"Mampir Ngombe" adalah film tari yang merefleksikan kondisi Pandemi Covid-19. Sejak akhir tahun 2019 hingga saat ini, seluruh manusia di bumi sedang menghadapi Pandemi dengan skala global. Memasuki tahun 2020 negara-negara di dunia mulai melakukan lockdown atau pembatasan sosial berskala besar bagi negaranya. Tingkat kematian akibat Pandemi Covid-19 ini selalu diberitakan melalui berbagai media setiap harinya, bahkan terdapat beberapa kerabat dan kawan yang terkonfirmasi positif Covid-19, hingga sembuh kembali namun juga ada yang meninggal. Duka dan kecemasan meliputi hampir disetiap harinya. Pandemi Covid-19 secara langsung dan tidak langsung memberi berbagai dampak. Salah satu dampak yang terjadi jika direnungkan secara dalam akan muncul suatu kesadaran, di mana hidup terasa benar-benar singkat bahwa setiap manusia tidak tahu kapan akan dipanggil pulang.Sebuah pepatah Jawa atau pitutur Jawa mengatakan "Urip iku mung sadermo mampir ngombe, yang memiliki arti hidup itu sangat singkat, ibarat hanya singgah minum. Pepatah itu menjadi sangat terasa pada kondisi saat ini. Waktu yang demikian singkat ini manusia diharapkan mengisinya dengan fikiran yang positif dan dan berusaha memanfaatkannya dengan melakukan hal-hal yang baik dan bermanfaat. Daripada hidup dalam ketakutan, kecemasan, dan kekuatiran, sebaiknya diisi dengan doa, serta belajar untuk ikhlas setiap harinya, hingga setiap langkah yang dijalani akan menjadi laku yang migunani tumpraping diri lan liya. Koreografer menggunakan media video/film sebagai media ungkap sebagai respons dan adaptasi pada kondisi Pandemi Covid-19. Pandemi Covid-19 membatasi gerak seni pertunjukan dalam hal ini tari yang secara normatif dapat dinikmati secara langsung oleh mata dan energi dirasakan hadir secara nyata, namun pada kondisi ini harus dinikmati melalui video/film. Karya ini merupakan sebuah ekperimentasi langkah baru bagi koreografer untuk mencoba dan berusaha mengekpresikan tari melalui media video/film dengan durasi 6.44 detik.

Kata kunci : Refleksi, Pandemi Covid-19, film tari. 


\begin{abstract}
The dance film entitled "Mampir Ngombe" with a short duration is a reflection and introspection on the current conditions of the Covid-19 Pandemic, all people on earth are facing a pandemic on a global scale since the end of 2019, entering 2020 countries in the world have begun. carry out lockdowns or large-scale social restrictions for the country. The death rate due to the Covid19 Pandemic is always reported through various news media every day, there are even some relatives and friends who have been confirmed positive for Covid-19, until they recover, but some have died. Grief and anxiety always cover almost every day. The Covid-19 pandemic directly and indirectly has various impacts. One of the impacts that occurs if you think about it deeply will emerge an awareness, where life feels really short that every human being does not know when to be called home. A Javanese proverb or Javanese pitutur "statesUrip iku mung sadermo mampir ngombe, which means life is like just stopping by for a drink, very briefly. The proverb is very pronounced in the current condition. This time is so short that humans are expected instead of every day filled with worries, fears and worries, it would be nice if they were filled with positive thoughts and and trying to make use of them by doing good and useful things, such as filling them with prayers, working with them. following health protocols, trying to live up to the advice from the government, namely Gerakan 5M Covid-19 (Wearing a mask, washing hands with soap with running water, keeping your distance, keeping away from crowds) and learning to do iklas every day, so that every step you take will become a practice that greeks tumpraping yourself lan liya. Choreographers use video / film media as a medium of expression as a response and adaptation to the conditions of the Covid-19 Pandemic. The Covid-19 pandemic limits the movement of performing arts, in this case dance, which can normally be enjoyed directly by the eye and the energy is felt to be present in real terms, but in this condition it must be enjoyed through videos / films. This work is an experimentation of a new step for choreographers to try and try to express dance through video / film media with short duration.
\end{abstract}

Keywords: Reflection, Covid-19 Pandemic, dance film.

\title{
I. PENDAHULUAN
}

Hidup Orang Jawa adalah sebuah (ora ana), madya (ana) menuju alam wasana perjalanan dari tiada menuju keketiadaan kembali. Perjalanan panjang, dari alam purwa (ora ana) (Endraswara, 2002:107) Alam purwa merupakan alam di mana manusia berawal 
mula. Madya ialah alam fana atau kehidupan manusia di dunia, dan alam wasana adalah alam akhir atau kelanggengan. Dalam budaya Jawa kehidupan manusia dimulai semenjak tumbuhnya bayi dalam kandungan ibu, kemudian setelah bayi dilahirkan dimulailah kehidupan yang sebenarnya di dunia. Makna ungkapan "Wong urip itu mung sadermo mampir ngombe", memiliki arti keberadaan manusia di dunia ini dipandang sangat singkat karena hanya singgah sebentar saja dan nantinya akan melanjutkan perjalan menuju ke alam selanjutnya, yaitu alam kelanggengan. Alam madya, yaitu kehidupan setelah manusia dilahirkan di dunia. Karena manusia hidup di "alam madya" ini hanya sebentar, waktunya hanya singkat, dibandingkan dengan di alam kelanggengan yang abadi, sudah sepantasnya kesempatan ini dipergunakan dengan sebaikbaiknya. Jika manusia melakukan banyak kebaikan di dalam hidupnya, tentu kelak akan memperoleh tempat yang baik pula di alam kelanggengan. Sebaliknya, bila berbuat buruk, maka di alam kelanggengan pun manusia akan mendapatkan tempat yang buruk.

Manusia, menurut budaya Jawa terlahir di dunia ini berbekal empat sifat dasar yang mewarnai kehidupannya, yang sering diistilahkan dengan aluamah, sefiah, amarah, dan mutmainah, atau yang biasa juga diistilahkan dengan nafsu angkara, amarah, keinginan dan perbuatan suci. Nafsu-nafsu tersebut timbulnya dirangsang oleh anasiranasir yang ada di dunia ini dan masuk melalui paningal (mata), pengucap (mulut), pangrungu (telinga), dan pangganda (hidung). Menguasai diartikan sebagai memelihara mengatur ataupun mengendalikan, yang dalam budaya Jawa diistilahkan dengan "wong urip iku mung sadermo mampir ngombe", haruslah disibukkan dengan tindakan-tindakan memelihara, mengatur serta mengendalikan keempat nafsu manusia ini, sehingga kehidupan di dunia yang sifatnya hanya sesaat tersebut diisi dengan kebajikan dan tindakan-tindakan terpuji, seperti tolong-menolong, mengasihi sesama, berbakti kepada nusa dan bangsa, saling hormat-menghormati, bermusyawarah, dan lain-lain.

Bagaimana agar seseorang dapat menguasai dan menjaga hati nuraninya terhadap nafsu? Budaya Jawa mengajarkan agar seseorang selalu menjalani laku, seperti berpuasa dan lain-lain, sebagai latihan pengendalian diri sehingga dapat mengendalikan diri apabila timbul rangsangan untuk bertindak yang tidak baik. Selain itu juga mengajarkan agar seseorang selalu mendekatkan diri kepada Tuhan Yang Maha Esa, sehingga selalu mendapatkan terang dariNya sebagai penunjuk jalan kebenaran dan dapat berpikir secara jernih dan bersih.

"Wong urip iku mung sadermo mampir ngombe" di alam kehidupan di dunia yang 
sesaat, manusia harus dapat mengisinya dengan tindakan baik. Diyakini salah satu tindakan yang pasti akan dilakukan pada kesempatan di dunia adalah belajar, belajar apapun untuk dapat memahami hakikat tentang berbagai ilmu sehingga kelak dapat berguna dan bermanfaat untuk menolong sesama. Ngombe adalah minum, minum adalah suatu tindakan untuk menghilangkan dahaga, kehausan hilang dahaga tersebut sampai puas. Jika telah lepas rasa haus tersebut maka tenaga akan pulih dan dapat melakukan kegiatan selanjutnya dengan baik. Manusia harus selalu belajar apapun untuk dapat mengatasi segala persolan yang dihadapi, manusia belajar untuk beradaptasi dengan alam dan lingkungan sosialnya. Apabila seseorang selalu ingat akan hal ini dan mengisi kehidupan sesaat dengan belajar segala sesuatu dengan bijak dan baik, hingga setiap ilmunya dapat bermanfaat untuk menolong sesama maka dapatlah diharapkan tujuan hidup seseorang akan tercapai, yaitu selamat di dunia maupun di alam kelak nanti. Mampir adalah singgah, singgah dilakukan ketika melakukan suatu perjalanan. Singgah dilakukan dengan singkat atau hanya sementara, maka kehidupan yang singkat dan sementara ini perlu dimanfaatkan sebaik-baiknya.

Media video/film dipakai sebagai media ungkap sebagai respons dan adaptasi pada kondisi Pandemi Covid-19. Pandemi Covid-19 membatasi gerak seni pertunjukan dalam hal ini tari yang secara normatif dapat dinikmati secara langsung oleh mata dan energi dirasakan hadir secara nyata, namun pada kondisi ini harus dinikmati melalui video/film. Karya ini merupakan sebuah ekperimentasi langkah baru bagi koreografer untuk mencoba dan berusaha mengekspresikan tari melalui media video/film dengan durasi pendek.

\section{PEMBahasan}

\section{A. Proses Pembuatan Karya}

Proses awal pembuatan karya ini diawali dengan diskusi mengenai konsep yang akan dihadirkan, ide cerita, dan plot-plotnya. Target karya ini hanya berdurasi lima menit hingga tujuh menit sehingga perlu adanya strategi bagaimana menghadirkan setiap plot adegan dengan ringkas, padat, namun dapat dipahami oleh penonton. Diskusi yang dilakukan juga berkaitan dengan hal-hal teknis persiapan dalam produksi film tari yang membutuhkan berbagai alat yang cukup banyak dan juga mempertimbangkan lokasi yang akan digunakan.

Riset awal mengenai konsep dilakukan secara mandiri melalui refrensi buku-buku, wawancara dengan berbagai sumber, serta melihat film-film tari pendek. Koreografer sendiri menganggap bahwa ini adalah sebuah eksperimentasi yang metode dan langkahlangkahnya masih perlu dijelajahi dan diujicoba dengan seksama. Film tari ini merupakah 
langkah awal sebuah riset bagi koreografer sebagi suatu pengalaman produksi film tari selanjutnya. Ketika konsep dan plot serta referensi yang telah didapat yaitu mengenai pepatah Jawa "Wong urip iku mung sadermo mampir ngombe" sebagai refleksi di tengah kondisi Pandemi Covid-19 ini, maka hal selanjutnya yang dilakukan adalah menentukan penari, pendukung, alat, lokasi, dan melakukan survey.

Koreografer harus menentukan lokasi yang memenuhi beberapa kriteria, selain sesuai dengan konsep garap tetapi juga lokasi yang strategis, aman dan mudah untuk melakukan produksi, terkait juga dengan diperlukannya aliran listrik untuk camera dan tempat transit yang aman dan nyaman digunakan oleh seluruh pelaku yang terlibat dalam produksi. Pemikiran tersebut didapat koreografer dari pengalaman sebelumnya terlibat dalam mengikuti beberapa produksi film.

Melalui diskusi dengan supervisor dan crew, maka lokasi yang dipilih di Sanggar Seni Bodoronoyo, Kulon Progo. Sanggar Seni Bodoronoyo ini terletak di deretean lereng bukit Menoreh dengan view lokasi yang indah serta fleksibel dan strategis untuk produksi film tari ini, dikarenakan aksesnya yang mudah dan sesuai dengan kriteria yang dibutuhkan. Selanjutnya survey dilakukan untuk melihat medan, area plot-plot yang akan digunakan, kelengkapan perlengkapan seperti aliran listrik dan keperluan lampu-lampu yang akan digunakan. Survey dilakukan jauh-jauh hari sebeleum hari shooting, agar jika terdapat kekurangan atau tidak sesuai dapat mencari alternatif lokasi yang lain. Sanggar Seni Bodronoyo sesuai dengan kriteria yang dibutuhkan dalam pembuatan film tari ini.

Langkah selanjutnya membuat alur kasar atau draf dan mencocokannya dengan lokasi yang telah disurvey, agar terjadi kesesuaian dengan konsep dan cerita yang akan dihadirkan. Draf kasar tersebut selanjutnya dikirimkan ke supervisor sebagai acuan persiapan saat shooting pengambilan gambar.

Penari dalam karya ini berjumlah empat perempuan dan satu perempuan sebagai ibu yang memang sedang mengandung. Perempuan dipilih sebagai bentuk simbol kekuatan dengan insting, naluri dan perasaanya ditengah pandemi saat ini. Perempuan dipilih sebagai representasi ibu yang mengayomi anakanaknya agar kuat dan tambah menghadapi cobaan. Perempuan mampu menjalani peran sebagai wanita yang harus kuat dan tabah serta mengayomi. Laku atau perjalan hidup wanita dari melahirkan dan merawat keluarga adalah inspirasi pemilihan penari perempuan. Jumlah empat memiliki makna keseimbangan empat sifat dasar yang mewarnai kehidupan.

Koreografer memiliki catatan motif dan gerak setiap adegan yang kemudian ditransfer pada penari. Koreografer sengaja melakukan 
latihan atau transfer gerak pada hari shooting pengambilan gambar saja karena kondisi pandemi saat ini, untuk mengantisipasi terlalu banyak pertemuan. Penari yang dipilihpun yang telah memiliki pengalaman dan handal dalam merekam hafalan gerak sehingga dengan cerdas dan cepat menerima transfer gerak dari koreografer. Di sini koreografer juga terlibat menjadi penari dikarenakan salah satu penari yang pada awalnya bisa terlibat, mendadak tidak bisa mengikuti proses karena jadwal lain yang bersamaan.

Kostum yang digunakan oleh empat penari perempuan berupa kebaya model kutu baru dengan berbagai corak motif yang berbeda, celana longgar berwarna coklat dan rambut dikepang. Untuk penari ibu menggunakan kebaya putih, selendang dan kain jarik batik motif Sidomukti. Kebaya di sini merupakan suatu bentuk rekontruksi budaya, mengenalkan kembali bentuk kutu baru, kebaya selain memiliki sisi elegan juga memiki makna kekuatan bagi perempuan untuk selalu kuat dan bangkit dalam menghadapi setiap tantangan.

Musik yang dipergunakan ialah musik digital record dengan vokal dan tembang Jawa yang dikomposeri oleh Ari Ersandi dan vocalis Renata Astria. Vocal yang digunakan adalah tembang dengan beberapa ornamen vocal suara.
Shooting pengambilan gambar dilaksanakan dengan efektif dan efisien dengan target selesai dalam waktu 1 hari. Cameraman menggunakan beberapa set lampu untuk adegan yang berada di Pendopo, selain adegan tersebut pencahyaannya murni menggunakan pencahayaan alami matahari, karena plot lainnya berada di outdoor dengan cuaca mendukung atau cerah. Sett dan property, bersifat natural lebih fokus pada pemandangan alam yang ada. Lokasi shooting pengambilan gambar ada di empat lokasi atau plot, yaitu Pendopo dengan setting kursi kayu panjang, teras pendopo dengan setting property lumpang, tepi rumah dengan latar jendela dan dinding rumah kayu dan tepi kolam dengan panorama gunung. Pengambilan gambar dimulai pukul 08.00 pagi dan selesai pada pukul 18.00 petang.

Selanjutnya editor melakukan editing, dengan memilih gambar-gambar yang sesuai dengan plot yang telah dibuat oleh koreografer. Editor juga selalu memberikan update perkembangan editing kepada koreografer. Dialog dilakuan melalui jaringan telfon dan chat aplikasi untuk menentukan gambargambar yang dipilih. Hasil editing yang yang telah tersusun kemudian direview bersama dan diskusi mengenai beberapa hal yang perlu diperbaiki. Hasil rekaman yang dipresentasikan cukup sesuai sehingga hanya perlu perbaikan- 
perbaikan seperti grading dan coloring untuk finalisasi.

\section{B. Hasil Karya}

Karya Film tari pendek ini dipentaskan di kanal Youtube Dinas Kebudayaan Provinsi DIY, dalam kegiatan Pentas Virtual Dinas Kebudayaan DIY. Film tari ini berjudul "Mampir Ngombe" dengan durasi 6.44 detik, sesuai dengan ketentuan dari penyelenggara pentas virtual. Film ini tampil perdana di kanal Youtube Dinas Kebudayaan DIY (tasteofjogja disbud diy) pada tanggal 10 Januari 2021, pada link:https://www.youtube.com/watch?v=VRX OB97KS2w.

Karya film tari berdurasi pendek ini memiliki empat plot adegan sebagai berikut:

\section{Lair}

Seorang perempuan yang sedang mengandung, berjalan pelan menuju ke tengah Pendopo, kemudian menari dengan pelan dan lembut di atas sebuah kursi kayu. Dengan hati yang gembira dan harap-harap cemas ia menantikan kelahiran si jabang bayi. Sang Ibu berkomunikasi dengan si jabang bayi, memberikan kasih sayang dan perhatian penuh terhadap si jabang bayi. Kasih dan perhatian seorang ibu untuk mempersiapkan manusia baru di dunia dengan memberikan ilmu dan asuhan tentang kebajikan dan kasih. Bayi disimbolisasikan oleh dua penari perempuan yang bergerak melingkar di atas meja. Dua penari perempuan merupakan simbol dua sisi manusia, baik dan buruk. Di dalam rahim ibu, bergerak memutar memegang selendang sebagai simbol plasenta, ikatan ibu dan anak serta ajaran-ajaran ibu yang diberikan pada anaknya melalui kasih sayang, dua sifat dasar tersebut tumbuh dalam pribadi manusia sejak masih dalam kandungan. Hingga saat manusia baru, si jabang bayi lahir berjalan di tengah kehidupan nyata bersama dua sifat tersebut selalu berdampingan. Setiap manusia memiliki pilihannya untuk berada pada sisi yang mana serta menyeimbangkannya.

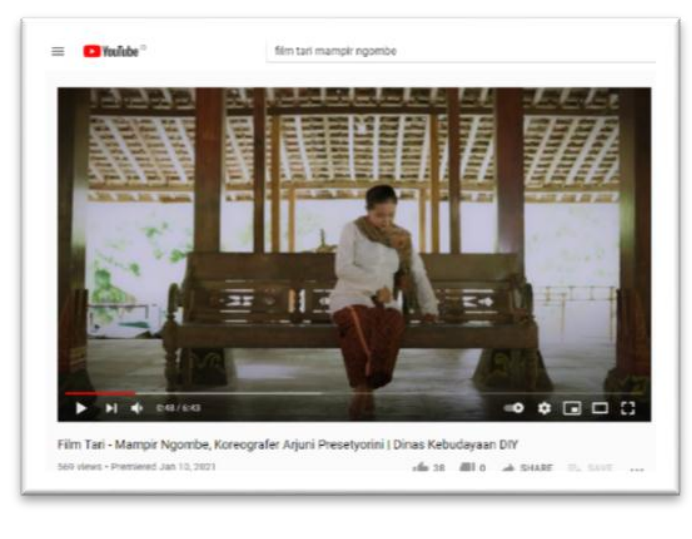

Gambar 1.Screenshoot Youtube, adegan Lair, Sang Ibu berkomunikasi dengan sijabang bayi.

\section{Ngombe}

Adegan ini dua penari perempuan bergerak saling berinteraksi dengan gerak tempo cepat dan tegas, merupakan penggambaran perjalanan manusia beranjak dewasa yang miliki tanggungjawab di dunia. Merupakan representasi alam Madya, alam tengah atau kehidupan dunia fana. Belajar menuntut ilmu, bekerja beribadah, saling tolong menolong adalah yang utama. Keseimbangan 
dan saling menopang di kehidupan manusia.

Saling berkomunikasi dan berinteraksi.

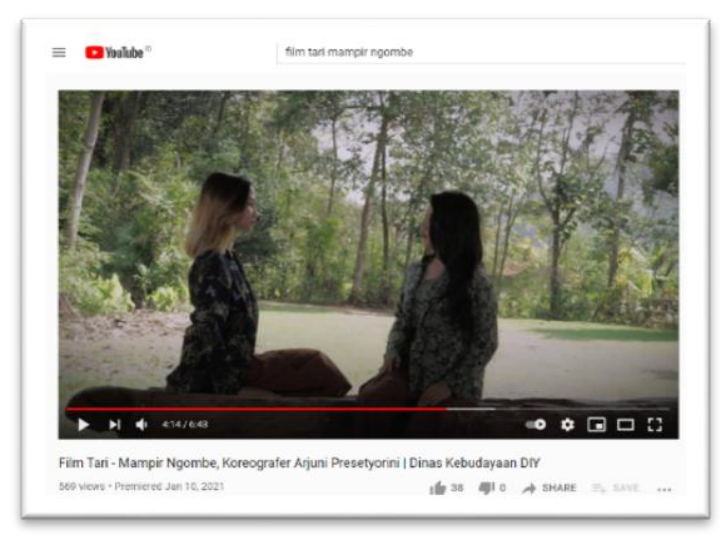

Gambar 2.Screenshoot Youtube,

adegan Ngombe, anak sedang belajar dan saling berinteraksi.

\section{Urip}

Empat penari perempuan melakukan gerak koreografi dan ekplorasi di teras yang sempit/tritisan dengan latar jendela dan dinding kayu. Adegan ini merupakan wujud penggambaran kehidupan yang singkat dan sempit, penari bergerak dengan sangat hati-hati dan saling berinteraksi, saling memberikan kesempatan bergerak di ruang yang sempit dan berpindah tempat, hingga masing-masing penari sebagai sosok manusia dapat memilih jalan yang akan dilalui. Bagian ini merupakan refleksi diri untuk memilih diam tak bergerak atau berani melangkah dengan kuat dan tegar. Perempuan pada masa ini dituntut untuk mampu menjalani berbagai peran kehidupan, tidak hanya ibu rumah tangga tetapi juga karir dan mimpi-mimpinya. Empat ssifat dasar manusia sebagai suatu keseimbangan yang akan terus mewarnai kehidupan manusia.

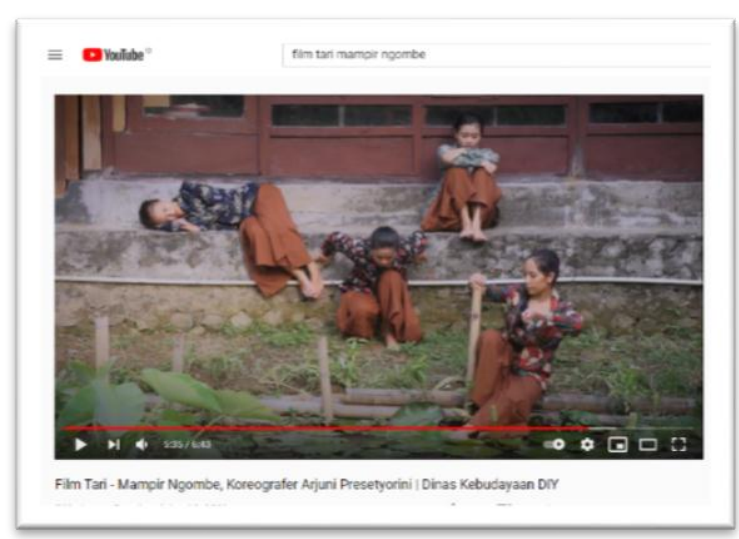

Gambar 3.Screenshoot Youtube, adegan Urip, perempuan-perempuan yang berjuang dan bekerja ditengah kondisi yang tidak menentu dan penuh kecemasan.

\section{Laku}

Pada waktu senja empat penari perempuan dengan membawa teko dan cangkir dari tanah liat, simbol ilmu pengetahuan dan tanggungjawab, berjalan dengan pelan, tenang namun pasti disetiap langkahnya beriringan dari satu titik awal ke titik selanjutnya, sebagai representasi perjalanan atau laku yang masih panjang untuk terus berjuang apapun keadaannya, tidak menyerah, berfikir positif dan fokus, belajar dan belajar untuk meraih mimpi dan masa depan dengan iringan doa. 


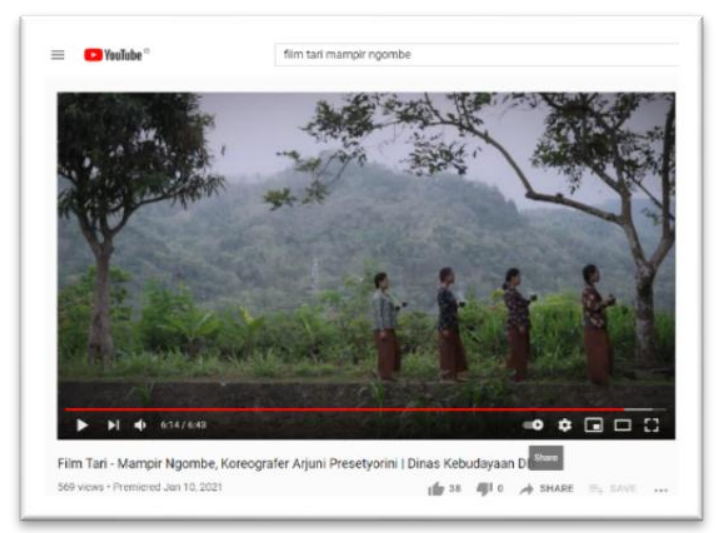

Gambar 4.Screenshoot Youtube,

adegan $L a k u$, representasi perjalanan atau laku yang masih panjang untuk terus berjuang apapun keadaannya.

\section{PENUTUP}

Tari adalah bahasa ungkapan jiwa yang diekpresikan melalui gerak-gerak. Pada kondisi normal pertunjukan tari dapat disaksikan secara langsung, namun ditengah kondisi Pandemi Covid-19 saat ini, tari dituntut dan mencoba menggunakan media baru sebagai bahasa ungkap ekpresinya, yang pada karya "Mampir Ngombe" ini adalah film tari berdurasi pendek. Film tari ini merupakan refleksi dan instropeksi atas kondisi pandemi saat ini dan yang masih berlangsung hingga entah kapan. Pemerintah dengan segala usaha, baik kebijakan PSBB/PSBK hingga vaksinasi terus diupayakan, agar kehidupan kembali normal. Sebagai seorang manusia yang saat ini berada pada kondisi ini, kita tidak boleh untuk panik, cemas dan gegabah dalam menghadapi, namun tetap berusaha dengan tenang, kuat dan tabah mencoba untuk terus berjalan ke depan, beradaptasi dengan kenormalan baru, memakai masker, menjaga jarak, selalu mencuci tangan dan menghindari kerumunan.

"Mampir Ngombe" adalah doa, bekerja, berusaha dan belajar mengendalikan diri, hidup berdampingan dengan alam dan sesama di tengah kondisi Pandemi saat ini. Hidup berdampingan dan diisi dengan kebajikan dan tindakan-tindakan terpuji, seperti tolongmenolong, mengasihi sesama, berbakti kepada nusa dan bangsa, saling hormat-menghormati, bermusyawarah untuk mencapai mufakat dan lain-lain. Hidup saling menghormati dan menghargai anugerah kehidupan ini telah diajarkan para leluhur tanah Jawa sejak dahulu kala dengan melakukan perbuatan yang baik dan bermanfaat. Manusia juga diingatkan bahwa "Urip iku mung sadermo mampir ngombe", sangat singkat ada suatu kelahiran, masa anak- anak bermain, masa dewasa dan turun ke dunia nyata, belajar, berusaha, bekerja dengan tanggung jawab dan selalu mengutamakan kebaikan hingga senja tiba dan waktu untuk pulang, segala yang telah dikerjakan di dunia ini memiliki makna dan bermanfaaat. Hal ini kembali harus dilakukan dan dimulai dari diri sendiri, keluarga, masyarakat di lingkungan terdekat dan akhirnya kepada seluruh dunia, agar tercapai hidup yang damai. Pandemi Covid-19 belum tahu kapan akan berakhir, namun manusia di bumi tidak boleh menyerah, harus tetap 
bergerak maju dengan memperbaiki diri dan masyarakat agar Bumi kembali pulih.

Adaptasi dan inovasi selalu diharapkan muncul untuk memberikan jalan ke luar atau solusi bagi keadaan yang tidak menentu. Dalam hal ini tari mencoba menggunakan alih media yaitu video/film sebagai sarana untuk tetap eksis menjaga keberlangsungan hidup tari. Hal ini merupakan sebuah usaha untuk tetap berkarya meskipun dalam kondisi Pandemi Covid-19.

\section{DAFTAR SUMBER ACUAN}

Anderson, Benedict R.O'G. (1965) Mythology and the Tolerance of the Javanese atau Mitologi dan Toleransi Orang Jawa, terjemahan Revianto B. Santoso dan Luthfi Wulandari. (2008), JEJAK, Yogyakarta.

Anderson, Janet. (2010), Modern Dance, Second Edition. Chelsea House, New York.

Achmad, Sri Wintala. (2012) Wisdom Van Java Mendedah Nilai-Nilai Kearifan Jawa. IN AzNa Books, Yogyakarta.

Achmad, Sri Wintala, (2017). Asal-usul \& Sejarah Orang Jawa, Yogyakarta, Araska.

Bing, Agus. "Tradisi Mencintai Bumi". Majalah Seni dan Budaya

GONG Edisi 71/VII/ 2005. Yogyakarta

Berger, Arthur Asa. (2005) Signs in Contemporary Culture, An Introduction to Semiotics atau Tanda-Tanda Dalam Kebudayaan Kontemporer, Suatu Pengantar Semiotika terjemahan M. Dwi Marianto, Tiara waca Yogya, Yogyakarta.

Brannigan, Erin. (2011) DancefilmChoreography and the Moving Image. Oxford University Press, Inc, New York
Brow, Jean Morison. (1998) Naomi Mindlin dan Charles H. Woodford. The Vision of Modern Dance, In The Words of Its Creators, Second Edition. Princenton Book Company, USA.

Caturwati, Endang. (2006). Perempuan dan Ronggeng, Pusat Kajian LBPB, Bandung.

Danesi, Marcel.(2004), Messages, Signs, Meanings: A Basic Texbook in Semiotic and Communication Theory (Third Edition) atau Pesan, Tanda dan Makna, Buku Teks Dasar Mengenai Semiotika dan Teori Komunikasi teerjemahan Evi Setyarini dan Lusi Lian Piantari. (2010), Jalasutra, Yogyakarta.

Endraswara, Suwardi. (2010) Falsafah Hidup Jawa, Menggali Mutiara Kebijaksanaan dari Intisari Filsafat Kejawen. Cakrawala, Yogyakarta.

Gere, David.(2004) How to Make Dances in an Epidemic-Tracking Choreography in the Age of AIDS,

The University of Wisconsin Press, London.

Gonzales, Joseph. (2004) Choreography, A Malaysian Perspective. Akademi Seni Kebangsaan, Kuala Lumpur.

Hadi,Y. Sumandiyo. (2004) Aspek-Aspek Dasar Koreografi Kelompok. ELKAPHI, Yogyakarta.

Hadi,Y. Sumandiyo. (2007) Pasang Surut Pelembagaan Tari Klasik Gaya Yogyakarta. Pustaka Book Publiser dan Lembaga Penelitian ISI Yogyakarta, Yogyakarta.

Hadi,Y. Sumandiyo. (2011) Koreografi, Bentuk, Teknik, Isi. Cipta Media bekerjasama dengan Jurusan Tari FSP ISI Yogyakarta, Yogyakarta.

Hadi,Y. Sumandiyo. (2012) Seni Pertunjukan dan Masyarakat Penonton. BP ISI Yogyakarta, Yogyakarta.

Hadikoesoemo, R.M. Soenandar. (1985) Filsafat Kejawaan Ungkapan Lambang Ilmu Gaib Dalam Seni Budaya Peninggalan Leluhur Jaman Purba. Yudhagama Corporation, Jakarta. 
Harymawan, RMA. (1993) Dramaturgi. PT Remaja Rosdakarya, Bandung.

Haryono, Timbul. (2009) Seni dalam Dimensi Bentuk, Ruang dan Waktu. Wedatama Widya Sastra, Jakarta.

Kaplan, David dan Robert A. Manners. (2012) The Theory of Culture atau Teori Budaya terjemahan Landung Simatupang. Putaka Pelajar Offset, Yogyakarta.

Hawkins, Alma. (2003) Moving From Whithin. A New Method For Dance Making atau, Bergerak Menurut Kata Hati terjemahan I Wayan Dibia. Masyarakat Seni Pertunjukan Indonesia, Jakarta.

Hawkins, Alma. (2006) Creating Through Dance atau Mencipta Lewat Tari terjemahan Y. Sumandiyo HadiManthili, Yogyakarta.

Hayuaji, Gangsar R. (2011) Centhini 3, Malam Ketika Hujan. Diva Press, Yogyakarta.

Herusatoto, Budiono. (2003) Simbolisme Dalam Budaya Jawa. Hanindita Graha Widia, Yogyakarta.

Hidajat, Robby. (2008) Seni Tari, Pengantar Teori dan Praktek Menyusun Tari bagi Guru. Jurusan Seni dan Desain Fakultas Sastra Universitas Negeri Malang, Malang.

Hobart, Angela dan Bruce Kapferer. (2005) Aesthetics in performance: Formations of Simbolic Contruction and Experience. Berghahn Books, United States

Kartika, Daharsono Sony. (2007) Estetika., Rekayasa Sains, Bandung.

Koentjaraningrat. Kebudayaan Jawa (1984), PN Balai Pustaka, Jakarta.

Kussudiardja, Bagong. (2000) Bagong Kussudiardja, Dari Klasik Hingga Kontemporer. Padepokan Press, Yayasan Bagong Kussudiardja. Yogyakarta.

Kussudiardja, Bagong. (2007) Joget mBagong di sebalik Tarian Bagong Kussudiardja, Padepokan Press, Yayasan Bagong Kussudiardja. Yogyakarta

Martono, Hendro. (2008) Sekelumit Ruang Pentas., Cipta Media, Yogyakarta.

Martono, Hendro. (2012) Koreografi Lingkungan. Cipta Media, Yogyakarta.
McPherson, Katrina. .(2006) Making Video Dance: A step-by-step guide to creating dance for the screen. Routledge, New York

Murgiyanto, Sal. (1986) Tari dalam Pengetahuan Elementer Tari dan Beberapa Masalah Tari., Direktorat Kesenian, Proyek Pengembangan Kesenian Jakarta, Jakarta.

Murgiyanto, Sal. (1993) Ketika Cahaya Merah Memudar, Sebuah Kritik Tari. Deviri Ganan, Jakarta.

Purwadi dkk. (2010) Upacara Pengantin Jawa.Panji Pustaka, Yogyakarta.

Purwadi. (2008) Kitab Jawa Kuno. Pinus, Yogyakarta.

Purwadi. (2012) Foklor Jawa. Pura Pustaka, Yogyakarta.

Ricour, Paul. (2012) Teori Interpretasi diterjemahkan oleh Masnur Hei. IRCiSoD, Yogyakarta.

Schechner, Richard. (2003) Performance Studies, An Introduction. Routledge, New York.

Schechner, Richard. (2006) Performance Studies, An Introduction, Second EditionRoutledge, New York.

Schlaich, Joan dan Betty DuPont. (1977) Dance The Art of Production. The CV Mosby Company, USA.

Setiawan, Erie. "Inisiasi: Pertaruhan Simbol dan Harapan", Majalah Seni dan Budaya GONG Edisi 118/XI/2010. Yogyakarta

Soedarsono, R.M. (1997) Wayang Wong, Dramatari Ritual Kenegaraan di Keraton Yogyakarta. Gadjah Mada University Press, Yogyakarta.

Soedarsono, R.M. (2002). Seni Pertunjukan Indonesia di Era Globalisasi. Gajah Mada University Press, Yogyakarta.

Smith, Jacqueline. (1985) Dance Composition: A Practical Guide For Teacher atau Komposisi Tari: Sebuah Petunjuk Praktis Bagi Guru. terjemahan Ben Suharto. IKALASTI, Yogyakarta. 
Sudarsono. (1977) Tari-Tarian Indonesia I. Proyek Pengembangan Media, Kebudayaan, Direktorat Jendral Kebudayaan, Departemen Pendidikan dan Kebudayaan, Jakarta.

Suharto, Ben. (1999) Tayub: Pertunjukan dan Ritus Kesuburan. Masyarakat Seni Pertunjukan Indonesia dan art.line atas bantuan Ford Foundation, Bandung.

Spradley, James P. Metode Etnografi. Tiara Wacana, Yogyakarta.

Sutrisno, Mudji. (2010) Ranah-Ranah Estetika Kanisius, Yogyakarta.

Sumaryono, (2016). Antropologi Tari Dalam Perspektif Indonesia, Yogyakarta: Media Kreativa.

Tilaar, Martha. (1999) Kecantikan Perempuan Timur. IndonesiaTera, Magelang.

Widaryanyo, FX. (2000) Memoar Ben Suharto, Bungah Ingaran Cubluk. Art.Line dan sePiring, Yogyakarta.

Yosodipuro, Marmien Sardjono. (1996) Rias pengantin Gaya Yogyakarta, Dengan Segala Upacaranya. Kanisius, Yogyakarta.

Yudiaryani. (2002). Panggung Teater Dunia

Perkembangan dan Perubahan Konvensi.

Pustaka Gondho Suli, Yogyakarta. 